\title{
Localization of Antibody-binding Sites by Sequence Analysis of Cloned Pilin Genes From Neisseria gonorrhoeae
}

\author{
By I. J. NICOLSON,${ }^{1}$ A. C. F. PERRY,${ }^{1} \dagger$ M. VIR JI, ${ }^{2}$ J. E. HECKELS ${ }^{2}$ AND \\ J. R. SAUNDERS ${ }^{1 *}$ \\ ${ }^{1}$ Department of Microbiology, University of Liverpool, PO Box 147, Liverpool L69 3BX, UK \\ ${ }^{2}$ Department of Microbiology, University of Southampton Medical School, Southampton General \\ Hospital, Southampton SO9 4XY, UK
}

(Received 24 November 1986)

Immunological analysis of gonococcal pilin (the protein structural subunit of pili) has demonstrated the existence of cross-reacting and type-specific epitopes. The role in adhesion of the domains represented by these epitopes remains unclear. DNA sequencing of a series of pilinexpressing ( $p i l E$ ) genes from a number of otherwise isogenic pilus antigenic variants combined with previous immunological analysis of the corresponding encoded pilins has allowed us to correlate certain predicted amino acid sequences with monoclonal antibody reactivities. The putative epitopes for type-specific antibodies lie predominantly in hydrophilic domains that also contain $\beta$ turns. The epitopes for type-specific monoclonal antibodies were shown to depend on amino acid changes either in three separated blocks of amino acid sequence in the semi-variable (SV) region of pilin, or in discrete regions that lie in the disulphide loop in the hypervariable (HV) region of the polypeptide. In contrast, antibody SM1, which reacts with all gonococcal pili, recognizes a poorly immunogenic region of moderate hydrophilicity but low turn potential lying in a conserved portion of the pilin molecule. Our results confirm that antibodies directed against epitopes in both the SV and HV regions are able to inhibit adhesion.

\section{INTRODUCTION}

Pili are major antigenic and virulence determinants in Neisseria gonorrhoeae and are believed to act as adhesins (Swanson, 1973; Punsalang \& Sawyer, 1973; Ward et al., 1974; Mardh \& Westrom, 1976). Antigenic variation of gonococcal pili involves the alteration of pilin gene sequences to produce immunologically variant pilus polypeptides (Hagblom et al., 1985; Segal et al., 1986). The process of antigenic variation is thought to involve complex recombination events between variant silent pilin gene sequences and pilin expression (pilE) loci that result, in some cases, in the production of novel pilin polypeptides (Segal et al., 1986; Haas \& Meyer, 1986). The $\mathrm{N}$-terminus of the polypeptide is constant whereas the remainder of the molecule, particularly the region within the disulphide loop near the C-terminus, is hypervariable (Haas \& Meyer, 1986; Hagblom et al., 1985; Segal et al., 1986). The HV region represents the immunodominant portion of the pilin molecule and antibodies in antisera raised against whole pili are directed mainly at this region (Schoolnik et al., 1984). Hitherto it has not been possible to assign epitopes for anti-pilus antibodies precisely to specific locations on pilin.

Cloning and sequencing of genomic DNA containing expressing pilE genes, rather than the direct primer extension sequencing of pilin-specific mRNA used by others (Bergstrom et al., 1986; Hagblom et al., 1985) has allowed us to analyse not only variant pilE genes per se, but also the immunological properties of the pilins they encode in Escherichia coli.

† Present address: Department of Biochemistry, University of Bristol, Bristol BS8 1TD, UK.

Abbreviations: HV, hypervariable; SV, semi-variable. 


\section{METHODS}

Bacterial strains, plasmids and bacteriophage. The variants of $N$. gonorrhoeae used have been described in detail elsewhere (Lambden et al., 1981). The recombinant pilin-expressing plasmids used are described by Nicolson $e t$ al. (1987). E. coli JM103 (Messing et al., 1981) was used as host for the propagation of M13 phage. M13 mp18 and mp19 (Norrander et al., 1983) were used for cloning and to provide single-stranded DNA template for sequencing.

Enzymes and isotopes. All restriction endonucleases, T4 DNA ligase and DNA polymerase I were obtained from Boehringer Mannheim. Reaction conditions for each enzyme were essentially as described by Maniatis $e t$ al. (1982). M13 universal DNA sequencing primer and $[\alpha-35 S] \mathrm{dATP} \alpha \mathrm{S}\left(>600 \mathrm{Ci} \mathrm{mmol}^{-1} ;>22 \mathrm{TBq} \mathrm{mmol}^{-1}\right)$ for DNA sequencing were purchased from Amersham.

Media and growth conditions. E. coli JM103 for transfections was cultured in $2 \times$ TY broth. M13 mp18 and mp19 recombinant plaques were isolated on $\mathrm{H}$ agar plates and viral particles were harvested after growth in $2 \times \mathrm{TY}$ broth as described in the Amersham International M13 Cloning and Sequencing Handbook.

DNA isolation and cloning methods. The isolation and characterization of variant pilE genes from $N$. gonorrhoeae P9 and subsequent analysis of the pilin genes and their expressed pilins have been described previously (Nicolson et al., 1987). Large-scale recombinant plasmid isolation was from chloramphenicol-amplified cultures of $E$. coli by the method of Humphreys et al. (1975). M13 mp18 and mp19 replicative form and single-stranded recombinant M13 DNA were isolated by the methods described in the Amersham International M13 Cloning and Sequencing Manual. Cloning procedures were essentially as described by Maniatis et al. (1982).

DNA sequencing. Restriction fragments from pilin-expressing pBR322 recombinants were subcloned into M13 mp18 and mp19 and sequenced using the dideoxy chain termination method (Sanger et al., 1977). A 0.5 kb Sau3A fragment harbouring all but the first 46 bp of the pilE gene from each recombinant plasmid (Nicolson et al., 1987) was cloned in both orientations into M13 mpl8 and subjected to DNA sequencing. The remaining pilE sequence (the coding region for the $\mathrm{N}$-terminus and promoter region) was determined by subcloning a $0.78 \mathrm{~kb} X b a \mathrm{I}-\mathrm{Sau} 3 \mathrm{~A}$ fragment into M13 mp19 and sequencing the recombinant phage. To assess the accuracy of this strategy, the DNA sequences of the $1.3 \mathrm{~kb} \mathrm{XbaI-BamHI}$ fragment of pLV270 and the $1.4 \mathrm{~kb} \mathrm{XbaI-ClaI}$ fragment of pLV260 were determined by sequencing a series of overlapping subfragments (unpublished). These fragments harbour the intact pilE gene and surrounding regions of each recombinant and the sequences were determined by DNA sequencing of both strands. The procedures for sequencing reactions and polyacrylamide gel electrophoresis were essentially as described previously (Walker et al., 1986).

Immunological reactivity. Immunological reactivity of cloned pilins was determined by 'dot blotting' of bacterial lysates as previously described (Nicolson et al., 1987) using monoclonal antibodies raised against pili of gonococcal strain P9 (Virji \& Heckels, 1983).

Analysis of predicted hydrophilicity and secondary structure. The predicted hydrophilicity of the deduced amino acid sequences was analysed using the algorithm of Hopp \& Woods (1981) averaging over six amino acid residues. Secondary structure predictions were made using the method of Chou \& Fasman (1978) as described by Corrigan \& Huang (1982).

\section{RESULTS AND DISCUSSION}

\section{DNA sequencing of representative pilE loci cloned from pilus variants of $N$. gonorrhoeae $P 9$}

A total of 12 classes of variant pilin genes was identified in gene libraries of $N$. gonorrhoeae (Fig. 1). The sequence of the first 53 amino acids of the mature pilin deduced from the DNA sequence is conserved in all P9 variants and is identical to the published sequence of the pilins produced by $N$. gonorrhoeae strain MS1 $1_{\mathrm{ms}}$ (Hagblom et al., 1985; Meyer et al., 1984). Only the translated DNA sequences corresponding to amino acid residues 50 to the $\mathrm{C}$-terminus of the representative variant pilins are shown. There are some minor differences in the conserved sequences of P9 and MS11 pilins (Hagblom et al., 1985). Some P9 variants had differences in the cys 1 region where single base changes resulted in the presence of new amino acids.

The overall arrangement of the variant pilin genes of strain P9 is similar to that described for pilE genes from strain MS11 ${ }_{\text {ms }}$ (Hagblom et al., 1985; Segal et al., 1986). Some variants are very similar to each other but most show considerable differences, mainly within the disulphide loop (Fig. 1). This region is characterized by in-frame deletions and numerous insertions and substitutions in the DNA sequence that substantially alter amino acid sequence. All the P9 pilin genes are different from those previously described, including the partial (silent) pilin copies located in the pilS1 region of MS11 $1_{\mathrm{ms}}$ (Bergstrom et al., 1986; Haas \& Meyer, 1986; Hagblom et al., 1985), demonstrating the extensive repertoire of gonococcal pilin genes. 
Correlation of pilin sequence with antibody reactivities

By comparing sequences of pilin variants it is possible to deduce the presence of unique tracts of amino acids that are invariably associated with reactivity for particular anti-pilus monoclonal antibodies (Fig. 1). These blocks of amino acids are thus certainly essential for the formation of particular epitopes if not constituting the epitope per se. Two separate classes of putative epitopes were found: one was characterized by extensive variation over well-separated portions of the molecule and the other by a small number of neighbouring changes in a single region.

The presence of an EcoRI site within the pilE gene of P9 pilus variants correlates with the expression of SM13-reactive pilins (Nicolson et al., 1987). Sequences unique to SM13-reactive clones allowed the tentative association of these regions with formation of the appropriate epitope (Fig. 1). The amino acids associated with this epitope are in three well-separated blocks (amino acid residues 56-63, 69-71 and 92-95), the coding sequence for one of which harbours part of the EcoRI site. If all three regions are required to constitute an SM13-reactive epitope then this particular antibody must recognize a discontinuous antigenic determinant (Barlow et al., 1986). Alternatively, only one or two of the three domains could be recognized by this antibody and the remaining regions may vary concomitantly but fortuitously with it.

In contrast, proposed epitopes recognized by antibodies SM3 (127-129), SM4 (127-129), SM5 (130-132) and SM6 (140-143) are located within the disulphide loop and result from only a small number of neighbouring amino acid deletions, substitutions and insertions. This suggests that relatively minor alterations are critical for the formation of certain epitopes. The precise extent of the epitopes for these antibodies cannot be deduced directly from these data, but the short regions required for recognition by the antibody would appear to be part of a continuous epitope. However, the epitopes for these antibodies are destroyed by treatment with mercaptoethanol and SDS, which suggests that they require a specific three-dimensional structure that is lost upon denaturation of the protein. Interactions with distant portions of the molecule might therefore be required to form a discontinuous epitope.

The putative epitopes for antibodies SM3, SM4 and SM5 are all located within a stretch of six amino acids at the C-terminal side of cys1. The putative epitope for SM6 is located closer to cys2 than cys 1 , implicating both these regions as major type-specific domains. The proposed locations of the type-specific epitopes recognized by SM3, SM4, SM5 and SM6 arc consistent with previous studies which suggested that they were each located in the same region of the pilin molecule, presumably in the HV region between cysl and cys2 (Virji \& Heckels, 1983; Virji et $a l ., 1983)$. In contrast, the type-specific epitope recognized by antibody SM13 apparently lies in the $S V$ region, which is also consistent with its more widespread distribution amongst the cloned pilins and strains other than the parent P9. Thus, epitopes in the SV as well as the HV regions contribute to the antigenic specificity of the pilin molecule.

\section{Predicted physical properties of pilins}

The relative hydrophobicity and predicted secondary structures of a number of $\mathrm{P} 9$ pilins were deduced from the predicted amino acid sequences. As would be expected from structural constraints, the hydrophobicity plots of each variant pilin were very similar, with the main differences occurring in the variable C-terminal region (Fig. 2). The putative epitopes for SM3, SM4, SM5 and part of the regions conserved in SM13-reactive pilins are located on strongly hydrophilic domains and in regions of high $\beta$ turn probability (Figs 2 and 3). Although the putative SM6 epitope and part of the SM13-reactive regions are in relatively less hydrophilic domains they are nevertheless also located within regions of high turn probability. Conformational analysis of the polypeptides predicted from translational open reading frames thus supports the positioning of the putative epitopes.

Localization of antibody-binding sites on predominantly hydrophilic domains and in regions of high turn probability strongly suggests that they are exposed on the mature pilus molecule and act as major immunogenic determinants.

Monoclonal antibody SM1, which reacts with all the cloned pilins, recognizes a weakly immunogenic epitope present in all gonococcal pili (Virji \& Heckels, 1983). In contrast to the other antibodies, the epitope reacting with SM1 is not destroyed by prior treatment of pili with 


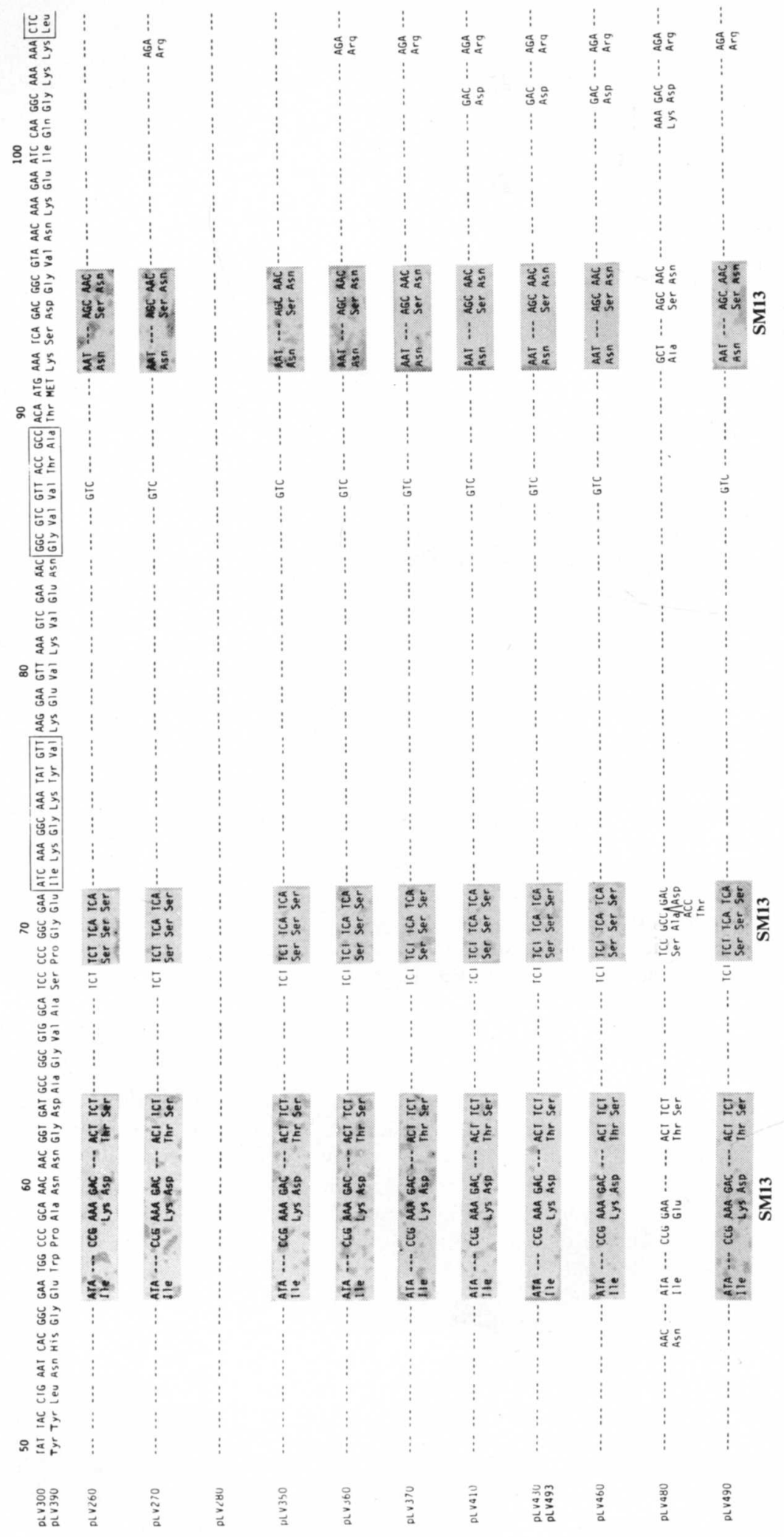




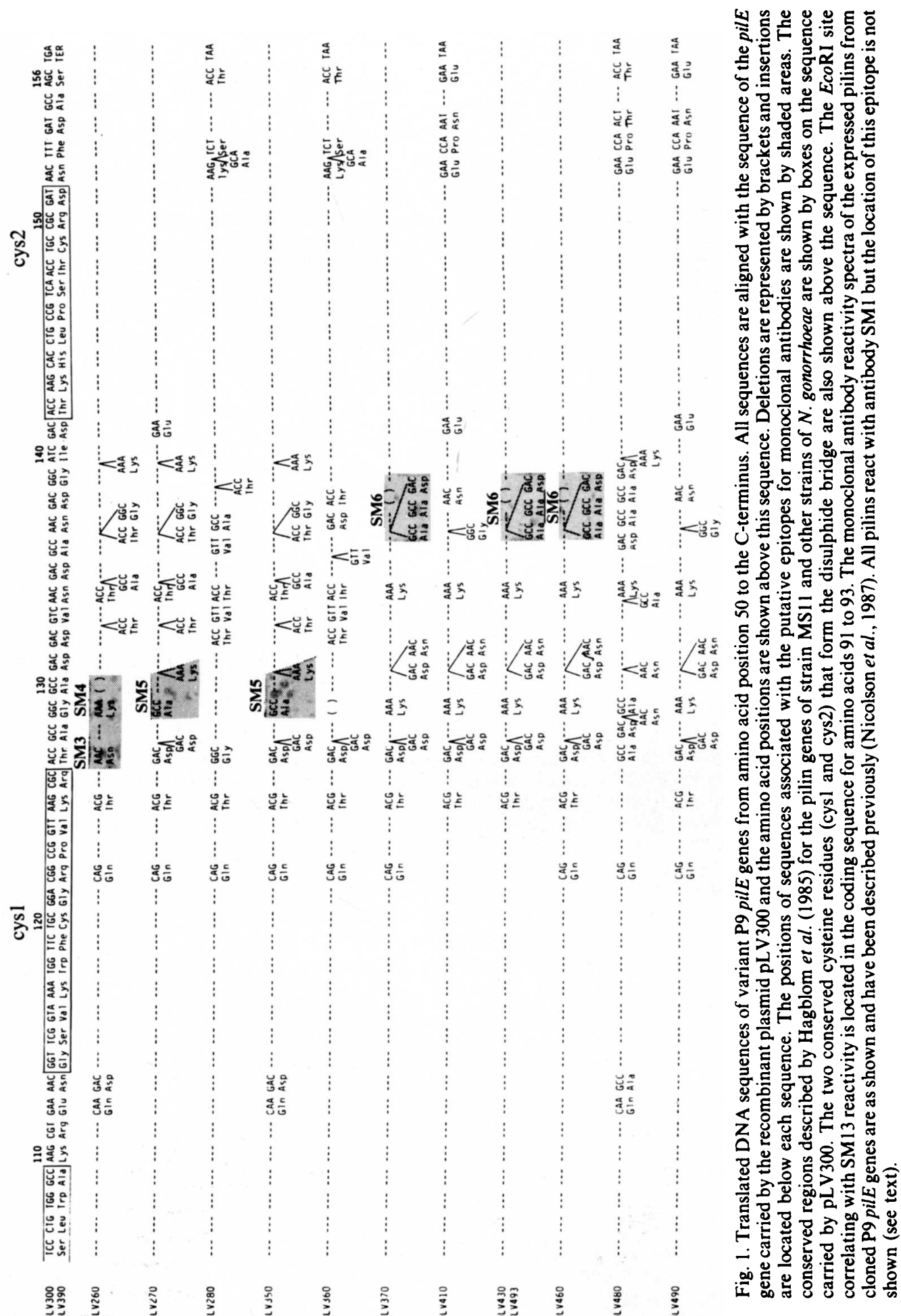



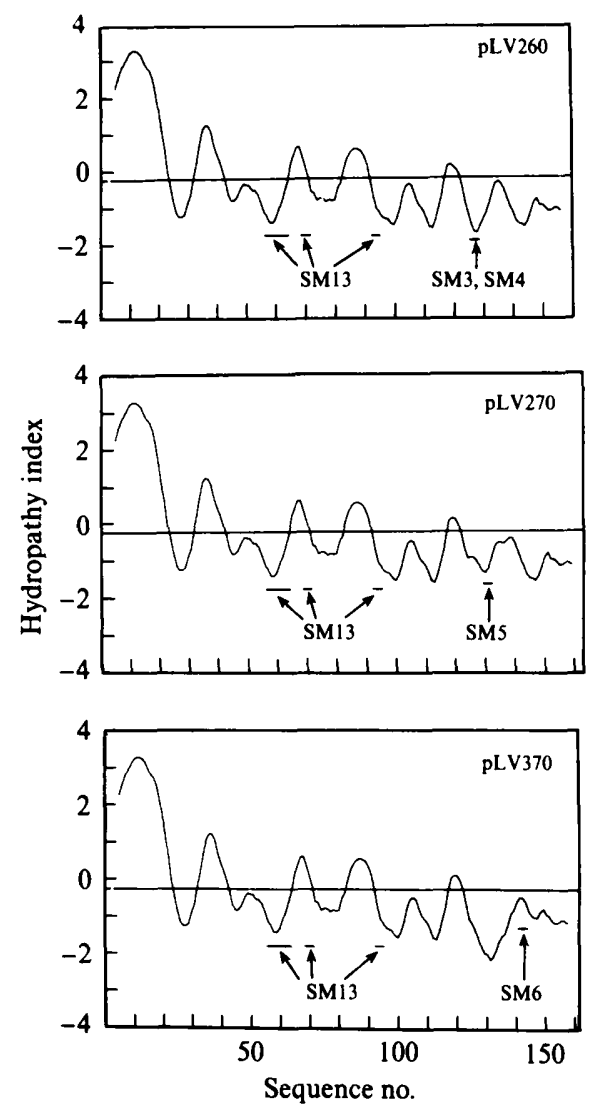

Fig. 2. Protein hydropathy predictions. The entire deduced amino acid sequences of three mature variant pilin polypeptides (encoded by recombinant plasmids pLV260, pLV270 and pLV370) were analysed for regions of relative hydrophilicity (negative values indicate hydrophilic domains). Arrows indicate regions associated with binding of each monoclonal antibody.

mercaptoethanol and SDS, suggesting a continuous linear epitope not dependent on tertiary structure. Antibody SMl also reacts with a synthetic peptide corresponding to amino acids 4860 of the pilin molecule (Heckels \& Virji, 1986). Since the cloned pilins show significant variation between residues 54-60 this defines the SM1 epitope as the region between amino acids 48 and 53. This poorly immunogenic epitope corresponds to a region of moderate hydrophilicity but low turn potential (Figs 2 and 3).

\section{Localization of functional domains on pilin}

The relative importance of type-specific and cross-reacting pilus epitopes in gonococcal attachment to host cells is controversial. Polyclonal anti-pilus antisera are effective in blocking the adhesion to human cells of gonococci that express the homologous pilin. In contrast, the antisera have little effect on attachment of heterologous pili (Virji et al., 1982) and the crossreacting monoclonal antibody SMl does not inhibit pilus binding (Virji \& Heckels, 1984). However, Rothbard et al. (1985), using antisera raised against synthetic pilus peptides, observed inhibition of pilus adhesion with antibodies directed against the conserved sequence 41-50 and the SV peptide 69-84, which contains a conserved sequence between amino acids $72-77$. In contrast, no inhibition was seen with antibodies directed against peptides 121-134 or 135-151 located in the HV region. They concluded that regions 41-50 and 69-84 were involved in receptor binding and that antibodies directed against the more immunogenic disulphide loop would not block adhesion. The monoclonal antibodies used here to characterize cloned pilins 

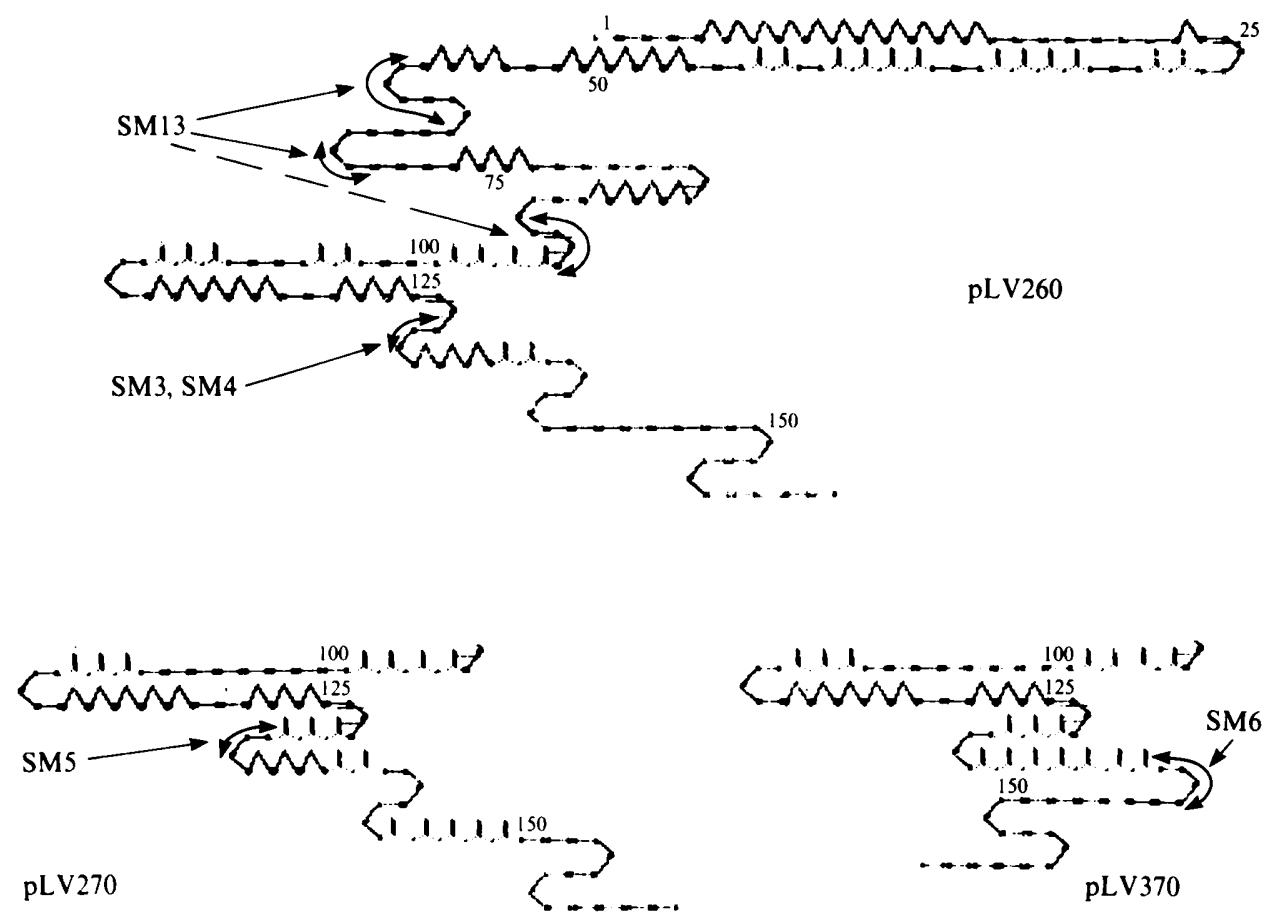

Fig. 3. Protein secondary structure predictions. The pilin sequences described in Fig. 2 were also subjected to secondary structure_analysis. The sequence for the pilin encoded by pLV260 is shown in full. Sequences for pilins encoded by pLV270 and pLV370 are shown only for the variable region extending from amino acid residue 95 to the C-terminus (the remainder of each of these sequences is identical to that of pLV260). Arrows indicate regions associated with binding of each monoclonal antibody. Secondary structure regions are represented as $\alpha$-helix ( $(\lambda=1$ amino acid), $\beta$-sheet ( $(\gamma=1$ amino acid), $\beta$-turn $(\zeta=2$ amino acids) and random coil ( $-=1$ amino acid).

have been utilized in previous studies to examine the role of gonococcal pili in pathogenesis and in particular, their effect on gonococcal attachment and virulence for various human cells (Virji \& Heckels, 1984). As might be expected from its recognition of epitopes close to the putative binding domain, antibody SM13 inhibited pilus binding. However, the other type-specific antibodies SM3, SM4, SM5 and SM6 were also effective in blocking pilus binding to epithelial cells. We have now localized regions of pilin sequence within the disulphide loop that apparently react with these antibodies, suggesting that the HV region may indeed contribute to pilus/cell adhesion.

Epitope localization on proteins is important for understanding the interactions of antibodies with specific regions on antigenic molecules. Epitopes have been localized on a number of proteins, including lysozyme (Benjamin et al., 1984), myoglobin (Westhof et al., 1984), myohaemerythrin (Tainer et al., 1984) and viral coat proteins (Altschuh et al., 1986; Colman et al., 1983; Rowlands et al., 1983), and on pili encoded by the F plasmid of E. coli (Frost et al., 1986). Comparison of related proteins with minor sequence alterations has been used to identify epitopes on insulin molecules (Rathjen \& Underwood, 1986). We have used sequence information to deduce the location of specific epitopes by analysis of highly variant pilus proteins produced by a single strain of $N$. gonorrhoeae. The association of particular domains with a specific function will therefore provide target regions for analysis by site-directed mutagenesis of the structure of gonococcal pili and their role in virulence.

We are grateful to Dr I. Giles, School of Biochemistry and Physiology, University of Southampton, for assistance with computation. I.J.N. and A.C.F.P. are grateful to the MRC and SERC respectively, for postgraduate scholarships. Part of this work was supported by grants from the Wellcome Trust to J.R.S. and from the MRC to J.E.H. 


\section{REFERENCES}

Altschum, D., Al Moudallal, Z., Briand, J. P. \& VAN REgenMORTEL, M. H. V. (1986). Immunochemical studies of tobacco mosaic virus. VI. Attempts to localize viral epitopes with monoclonal antibodies. Molecular Immunology 22, 329-337.

Barlow, D. J., EdWARds, M. S. \& ThORNTON, J. M. (1986). Continuous and discontinuous protein antigenic determinants. Nature, London 322, 747748.

Benjamin, D. C. Berzofsky, J. A., EAst, I. J., Gurd, F. R. N., Hannum, C., Leach, S. J., Margoliash, E., Michael, J. G., Miller, A., Prager, E. M., Reichlin, M., Sercarz, E. E., SMith-Gill, S. J., ToDD, P. E. \& Wilson, A. C. (1984). The antigenic structure of proteins: a reappraisal. Annual Review of Immunology 2, 67-101.

Bergstrom, S., Robbins, K., Koomey, J. M. \& Swanson, J. (1986). Piliation control mechanisms in Neisseria gonorrhoeae. Proceedings of the National Academy of Sciences of the United States of America 83, 3890-3894.

Chou, P. Y. \& Fasman, G. D. (1978). Prediction of the secondary structure of proteins from their amino acid sequence. Advances in Enzymology 47, 45148.

Colman, P. M., Varghese, J. N. \& Laver, W. G. (1983). Structure of the catalytic and antigenic sites in influenza virus neuraminidase. Nature, London 303, 41-44.

Corrigan, A. J. \& Huang, P. C. (1982). A BASIC microcomputer program for plotting the secondary structure of proteins. Computer Programs in Biomedicine 15, 163-168.

Frost, L. S., Lee, J. S., Scraba, D. G. \& Paranchych, W. (1986). Two monoclonal antibodies specific for different epitopes within the amino-terminal region of F pilin. Journal of Bacteriology 168, 192-198.

HAAS, R. \& MEYER, T. F. (1986). The repertoire of silent pilus genes in Neisseria gonorrhoeae: evidence for gene conversion. Cell 44, 107-115.

Hagblom, P., Segal, E., Billyard, E. \& So, M. (1985). Intragenic recombination leads to pilus antigenic variation in Neisseria gonorrhoeae. Nature, London 315, 156-158.

HeCKels, J. E. \& VIRJI, M. (1986). Antigenic variation of gonococcal surface proteins: effect on virulence. In Protein-Carbohydrate Interactions in Biological Systems, pp. 89-94. Edited by D. L. Lark. London: Academic Press.

Hopp, T. P. \& Woods, K. R. (1981). Prediction of protein antigenic determinants from amino acid sequences. Proceedings of the National Academy of Sciences of the United States of America 78, 38243828.

Humphreys, G. O., Willshaw, G. A. \& ANDERSON, E. S. (1975). A simple method for the preparation of large quantities of pure plasmid DNA. Biochimica et biophysica acta 383, 457-463.

Lambden, P. R., Heckels, J. E., McBride, H. \& WATT, P. J. (1981). The identification and isolation of novel pilus types produced by variants of Neisseria gonorrhoeae $\mathrm{P9}$ following selection in vivo. FEMS Microbiology Letters 10, 339-341.

Maniatis, T., Frisch, E. F. \& SambrooK, J. (1982). Molecular Cloning: a Laboratory Manual. Cold
Spring Harbor, NY: Cold Spring Harbor Laboratory.

Mardi, P. A. \& Westrom, L. (1976). Adherence of bacteria to vaginal epithelial cells. Infection and Immunity 13, 661-666.

Messing, J., Crea, R. \& Seeburg, P. H. (1981). A system for shotgun DNA sequencing. Nucleic Acids Research 9, 309-321.

Meyer, T. F., Billyard, E., HaAs, R., Storzbach, S. \& So, M. (1984). Pilus genes of Neisseria gonorrhoeae: chromosomal organization and DNA sequence. Proceedings of the National Academy of Sciences of the United States of America 81, 61106114.

Nicolson, I. J., Perry, A. C. F., Heckels, J. E. \& SAUNDERS, J. R. (1987). Genetic analysis of variant pilin genes from Neisseria gonorrhoeae $\mathrm{P9}$ cloned in Escherichia coli: physical and immunological properties of encoded pilins. Journal of General Microbiology 133, 553-561.

Norrander, J., Kempe, T. \& Messing, J. (1983). Improved M13 vectors using oligonucleotidedirected mutagenesis. Gene 26, 101-106.

Punsalang, A. P. \& Sawyer, W. D. (1973). Role of pili in the virulence of Neisseria gonorrhoeae. Infection and Immunity 8, 255-263.

RATHJEN, D. A. \& UNDERWOOD, P. A. (1986). Identification of antigenic determinants on insulin recognised by monoclonal antibodies. Molecular Immunology 23, 441-450.

Rothbard, J. B., Fernandez, R., Wang, L., Teng, N. N. H. \& SchoolnIK, G. K. (1985). Antibodies to peptides corresponding to a conserved sequence of gonococcal pilins block bacterial adhesion. Proceedings of the National Academy of Sciences of the United States of America 82, 915-919.

Rowlands, D. J., Clarke, B. E., Carroll, A. R., Brown, F., Nicholson, B. H., Bittle, J. L., Houghton, R. A. \& LeRner, J. L. (1983). Chemical basis of antigenic variation in foot-and-mouth disease virus. Nature, London 306, 694-697.

Sanger, F., Nicklen, S. \& Coulson, A. R. (1977). DNA sequencing with chain terminating inhibitors. Proceedings of the National Academy of Sciences of the United States of America 74, 5463-5467.

Schoolnik, G. K., Fernandez, R., TaI, J. Y., Rothbard, J. \& Gotschlich, E. C. (1984). Gonococcal pili: primary structure and receptor binding domain. Journal of Experimental Medicine 159, 13511370.

Segal, E., Hagblom, P., Seifert, H. S. \& So, M. (1986). Antigenic variation of gonococcal pilus involves assembly of separated silent gene segments. Proceedings of the National Academy of Sciences of the United States of America 83, 2177-2181.

Swanson, J. (1973). Studies on gonococcal infection. IV. Pili: their role in attachment of gonococci to tissue culture cells. Journal of Experimental Medicine 137, 571-589.

Tainer, J. A., Getzoff, E. D., Alexander, H., Houghten, R. A., Olson, A. J. \& Lerner, R. A. (1984). The reactivity of anti-peptide antibodies is a function of the atomic mobility of sites in a protein. Nature, London 312, 127-133.

VIRJI, M. \& Heckels, J. E. (1983). Antigenic cross- 
reactivity of Neisseria pili: investigations with typeand species-specific monoclonal antibodies. Journal of General Microbiology 129, 2761-2768.

VIRJI, M. \& HECKELS, J. E. (1984). The role of common and type-specific pilus antigenic domains in adhesion and virulence of gonococci for human epithelial cells. Journal of General Microbiology 130, 10891095.

VirJi, M., Everson, J. S. \& Lambden, P. R. (1982). Effect of anti-pilus antisera on virulence of variants of Neisseria gonorrhoeae for cultured epithelial cells. Journal of General Microbiology 128, 1095-1100.

VIRJ, M., Heckels, J. E. \& WATT, P. J. (1983). Monoclonal antibodies to gonococcal pili: studies on antigenic determinants on pili from variants of strain P9. Journal of General Microbiology 129, 19651973.

WALKer, J. N. B., DeAN, P. D. G. \& SAunders, J. R. (1986). Identification and characterization of PmaCI, an endonuclease of novel specificity from Pseudomonas maltophila. Nucleic Acids Research 14, 1293-1301.

WARD, M. E., WATt, P. J. \& Robertson, J. N. (1974). The human fallopian tube: a model for gonococcal infection. Journal of Infectious Diseases 129, 650-659.

Westhof, E., Altschuh, D., Moras, D., Bloomer, A. C., Mondragon, A., Klug, A. \& Van RegenMORTEL, M. H. V. (1984). Correlation between segmental mobility and the location of antigenic determinants in proteins. Nature, London 311, 123-126. 